
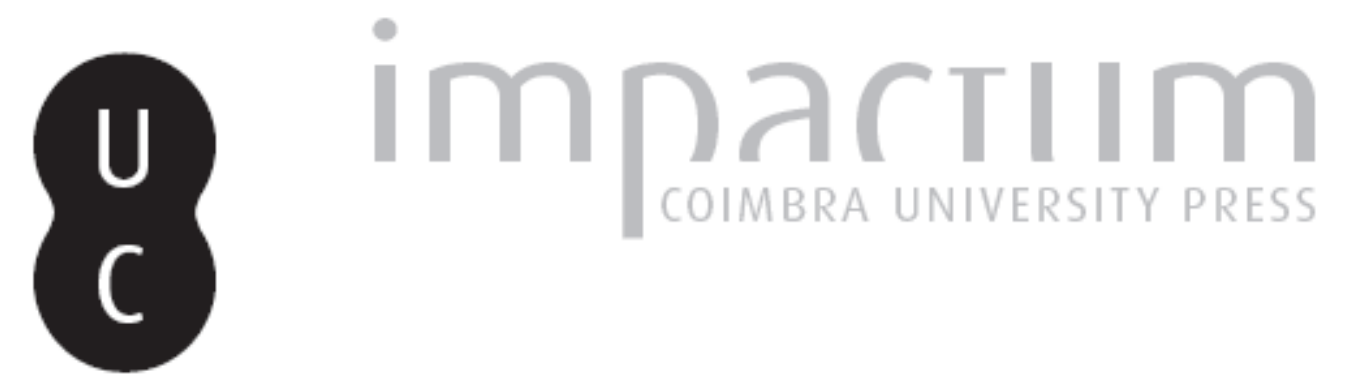

\title{
A especialização como ideia força em quatro teses de doutoramento em Geografia Física defendidas em 1994 e 1995
}
Autor(es):
Rebelo, Fernando

Publicado por: Associação Portuguesa de Riscos, Prevenção e Segurança

URL persistente:

URl:http://hdl.handle.net/10316.2/40180

DOI:

DOI:https://doi.org/10.14195/1647-7723_2_6

Accessed : $\quad$ 26-Apr-2023 10:42:31

A navegação consulta e descarregamento dos títulos inseridos nas Bibliotecas Digitais UC Digitalis, UC Pombalina e UC Impactum, pressupõem a aceitação plena e sem reservas dos Termos e Condições de Uso destas Bibliotecas Digitais, disponíveis em https://digitalis.uc.pt/pt-pt/termos.

Conforme exposto nos referidos Termos e Condições de Uso, o descarregamento de títulos de acesso restrito requer uma licença válida de autorização devendo o utilizador aceder ao(s) documento(s) a partir de um endereço de IP da instituição detentora da supramencionada licença.

Ao utilizador é apenas permitido o descarregamento para uso pessoal, pelo que o emprego do(s) título(s) descarregado(s) para outro fim, designadamente comercial, carece de autorização do respetivo autor ou editor da obra.

Na medida em que todas as obras da UC Digitalis se encontram protegidas pelo Código do Direito de Autor e Direitos Conexos e demais legislação aplicável, toda a cópia, parcial ou total, deste documento, nos casos em que é legalmente admitida, deverá conter ou fazer-se acompanhar por este aviso.

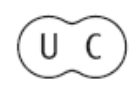




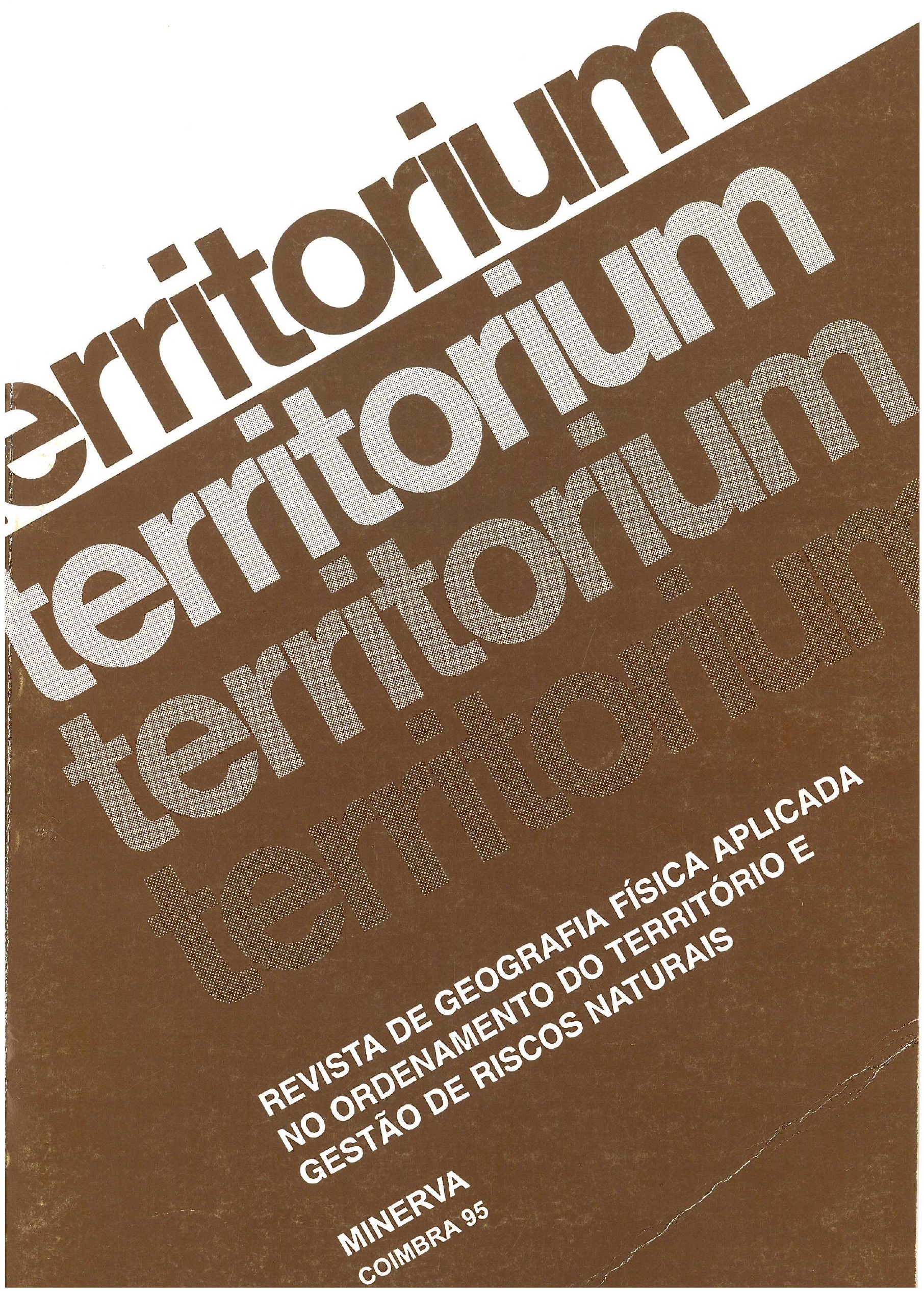




\title{
NOTAS, NOTÍCIAS E RECENSÕES
}

\author{
A especialização como ideia força em quatro teses de \\ doutoramento em Geografia Física defendidas em \\ 1994 e 1995
}

\section{Fernando Rebelo}

1.Em 1994, doutorou-se, na Faculdade de Ciências Sociais e Humanas da Universidade Nova de Lisboa, MARIA JOSÉ ROXO. Elaborada na área da Geografia Física, a tese que apresentou intitulava-se $A$ acção antrópica no processo de degradação de solos. A Serra de Serpa e Mértola. Tal como seria de esperar num trabalho deste género, a Autora deu uma grande importância às características da precipitação na área de estudo, mas não subestimou características hidrológicas, geomorfológicas e até pedológicas logo no primeiro capítulo. O homem aparece no segundo capítulo numa perspectiva fortemente histórica, mas o fulcro da tese encontra-se nos terceiro e quarto capítulos, quando MARIA JOSÉ ROXO se debruça finalmente sobre os casos concretos que estudou em talhões de erosão no Campo Experimental de Vale Formoso.

Na mesma Escola, mas já em 1995, doutorou-se JOSÉ VENTURA, também com uma tese de Geografia Física, muito bem definida na área da Climatologia, que intitulou As precipitações no Sul de Portugal (ritmo e distribuição espacial). O trabalho começa por tratar da "variabilidade temporal e espacial das precipitações" (primeira parte) e culmina com um estudo sobre "a escassez e a abundância das precipitações" (segunda parte). Naturalmente, ganham aí muita importância "os episódios de seca" e "os episódios muito chuvosos" (1).

2. Condições geomorfológicas e climáticas das cheias da Ribeira de Tera e do Rio Maior (Bacia hidrográfica do Tejo) foi o título dado por MARIA CATARINA DE MELO RAMOS à tese de Doutoramento em Geografia Física que defendeu na Universidade de Lisboa, em 24 de Janeiro de 1995.

(1)Os nossos agradecimentos à Prof. Doutora Zília Osório de Castro que nos facultou fotocópias dos índices destas duas teses.
$\mathrm{Na}$ sua forma actual, corresponde a um livro policopiado com 520 páginas, onde, além de um texto, bem escrito e bem revisto, com pouquíssimas "gralhas", se incluem 61 quadros, 137 figuras e 45 fotografias, que fornecem uma boa ilustração.

CATARINA RAMOS estruturou a sua tese em duas partes de tamanhos desiguais, depois de uma curta "Introdução" (7 páginas) e antes de um capítulo a que chama "Conclusões finais" (13 páginas). A primeira parte (102 páginas) pretende dar um enquadramento hidrológico às duas bacias-vertente escolhidas e a segunda (349 páginas) corresponde ao estudo das suas dinâmicas hidrológicas. Salientemse aqui os estudos de casos concretos de inundações cujos efeitos acompanhou no campo; as fotografias que apresenta falam por si.

Tratando-se da primeira tese de Geografia Física elaborada em Portugal na área da Hidrologia, tornase particularmente importante a extensa "Bibliografia" (18 páginas) que a Autora achou por bem juntar no fim do trabalho.

3. A tese de doutoramento defendida por ANTONIO CAMPAR DE ALMEIDA na Universidade de Coimbra (29 de Maio de 1995) intitula-se Dunas de Quiaios, Gândara e Serra da Boa Viagem. Uma abordagem ecológica da paisagem. Trata-se de uma tese de Geografia Física, no sentido mais amplo do termo, mas a especialização nota-se bem através do maior aprofundamento do estudo no ramo da Biogeografia.

Na sua forma de livro policopiado, a tese tem 305 páginas de texto, onde se incluem 100 figuras e 30 quadros, às quais se juntam 35 fotografias a cores organizadas em 9 estampas extra-texto encontrando-se estruturada em seis capítulos.

O primeiro é a "Introdução" (p. 1-27) e o segundo a apresentação do "Quadro natural da área em estudo" (p. 29-83), que se inicia pelo clima, passa pelas 
características geológicas e geomorfológicas e termina nos solos e na vegetação.

O terceiro é a "Caracterização biofísica das Dunas de Quiaios" (p. 85-124), o quarto a "Caracterização biofísica da Gândara" (p. 125-144) e o quinto a "Caracterização biofísica da Serra da Boa Viagem" (p. 145-215). Estes três capítulos são o fulcro da tese e, como seria de esperar pela repetição dos seus títulos, apresentam uma estrutura muito semelhante. Em cada um deles tudo começa por uma apresentação das linhas gerais da paisagem, com textos que, até do ponto de vista literário, dão gosto ler; segue-se a caracterização e distribuição das componentes analisadas, ou seja, das componentes geomorfológicas, das componentes pedológicas e das componentes florísticas. Só o quinto capítulo, por se dedicar a uma unidade rica em diversidade, tem um pequeno subcapítulo a mais que os outros - "topoclimatologia". O último capítulo, o sexto, intitula-se "Dinâmica da paisagem. Síntese e conclusão" (p. 217-256) e dá algumas ideias sobre a aplicação possível destes estudos no âmbito do ordenamento do território. Seguem-se a indicação da "Cartografia e fotografia de apoio" e as "Referências bibliográficas" (p. 257270 ), bem como algumas páginas de anexos e índices (p. 271-305).

\title{
Seminário Internacional sobre Fogos Florestais
}

\author{
Vilamoura (7 e 8 de Abril de 1995)
}

\section{Luciano Lourenço}

Atenta às grandes questões que preocupam os cidadãos, a Associação Nacional de Municípios Portugueses quis analisar, com o pormenor requerido, um tema que, com maior ou menor gravidade, todos os anos, durante o período estival, afecta a maioria dos municípios do nosso país.

No entanto, os fogos florestais constituem uma preocupação comum a todos os povos da Europa Mediterrânea, razão pela qual, desde logo, se entendeu .curial envolver também representantes dos países mediterrâneos.

Além disso, considerou-se que a problemática deveria ser analisada globalmente, portanto, nas suas três componentes (antes, durante e após o fogo), ou seja, naquelas que se relacionam, directamente, com prevenção, combate e efeitos dos incêndios florestais, de modo a que fosse englobada toda a conjuntura com eles relacionada.

Estes aspectos, entendidos como principais linhas de acção para uma análise circunstanciada da problemática que envolve o fogo florestal, constituiram os três temas centrais do Seminário, cada um dos quais foi abordado através de um painel específico.

Depois desta análise, restava saber qual será o futuro que espera a floresta das regiões mediterrâneas, motivo porque este tema centralizou a discussão do quarto painel em debate.
Pela sua natureza, este painel teve uma estrutura ligeiramente diferente da apresentada pelos restantes, na medida em que se privilegiaram sobretudo as opiniões daqueles que podem decidir sobre o futuro da Europa.

Nos restantes painéis, a estrutura inicialmente prevista para cada um dos temas envolvia intervenções de um representante das Associações congéneres da ANMP, representativas dos outros quatro países do Sul da Europa - Espanha, França, Itália e Grécia, de um perito europeu, do Presidente do Instituto ou do Serviço Nacional responsável mais ligado ao tema em análise, respectivamente Instituto Florestal, Serviço Nacional de Bombeiros e Instituto de Conservação da Natureza, de um investigador universitário português e, no caso do segundo painel, de um representante dos municípios portugueses.

A apresentação destes painéis foi antecedida por duas conferências da responsabilidade do Prof. Doutor Fernando Rebelo ("A FLORESTA NO MUNDO GRANDES INCÊNDIOS FLORESTAIS") e do Eng . Maia Costa, Presidente da CNEFF (FOGOS FLORESTAISEMNÚMERO-UNIÃOEUROPEIA), com as quais se pretendeu situar a problemática dos fogos florestais num contexto mundial e europeu, antes de se passar a uma análise mais minuciosa e circunstanciada do problema nos países mediterrâneos, com particular destaque para Portugal. 